Poster Section

\title{
Flow cytometric analysis of the inhibition of human basophil activation by histamine high dilutions - a replication study
}

\author{
Chantal Wälchli, Stephan Baumgartner \\ Institute of Complementary Medicine KIKOM, University of Bern, Bern, Switzerland \\ Centre for Integrative Medicine, University of Witten-Herdecke, Germany \\ Society for Cancer Research, Hiscia Institute, Arlesheim, Switzerland
}

\begin{abstract}
Background: Inhibition of human basophil activation by highly diluted histamine was reported to be a reliable experimental model to examine biological effects of high dilutions. However, independent replications did not always yield concordant results.
\end{abstract}

Aims: We aimed at performing an independent replication of a former study [1] using rigorously controlled experimental conditions to minimise confounding factors.

Materials and Methods: In 20 independent experiments, human basophils were treated with highly diluted histamine $\left(15 \mathrm{cH}, 16 \mathrm{cH}\right.$, corresponding to $\left.10^{-30}-10^{-32} \mathrm{M}\right)$ prior to activation by fMLP (formyl-methionyl-leucylphenylalanine peptide). Controls were treated with analogously diluted water $(15 \mathrm{cH}, 16 \mathrm{cH})$. The dilutions were prepared freshly for each experiment in deionised water by successive steps of centesimal dilution and agitation (10 s vortex at high speed). Highly diluted samples were blinded and randomised. All samples were set in triplicates. Activated basophils were determined by flow cytometry using anti-CD203c. 20 independent systematic negative control (SNC) experiments were carried out to investigate possible systematic errors.

Results: No difference in basophil activation was observed between the highly diluted histamine samples and the highly diluted water controls. There was no evidence for a blood donor specificity of the results. The SNC experiments demonstrated the stability of the test system. Experimental variability within and between experiments was slightly reduced for the highly diluted histamine samples.

Discussion: This study was designed as an independent reproduction of a former study [1]. Though we strictly adopted the experimental procedure described in [1], our results do not confirm the large inhibitory effects observed for histamine $15 \mathrm{cH}$ and $16 \mathrm{cH}$. This lack of reproducibility might be due to minor differences in the experimental design, such as blinding and randomising of the samples, which we chose to perform in order to reduce the possibility of artifacts but was omitted in the former study.

Conclusions: Laboratory independent replication of homeopathic basic research experiments is still a challenge. Assuming that the results formerly obtained with this model were not due to systematic errors, the quest identifying the crucial factors for successful reproducibility is open for future research.

Keywords: Human basophils; histamine; high dilutions; flow cytometry 


\section{Reference:}

[1] Sainte-Laudy J, Belon P. Improvement of flow cytometric analysis of basophil activation inhibition by high histamine dilutions. A novel basophil specific marker: CD 203c. Homeopathy. 2006;95:3-8.

\section{(cc) EY-NC-ND Licensed to GIRI}

Support: This study was funded by the Laboratoires Boiron, Sainte Foy Lès Lyon, France. The sponsor had no influence whatsoever upon study design, data collection, data analysis and interpretation of data. The authors had full access to all data and take complete responsibility for the integrity of the data and for the accuracy of data analysis.

Conflict of interest: authors declare there is no conflict of interest.

Received: 01 June 2012; Revised: 09 August 2012; Published: 30 September 2012.

Correspondence author: Stephan Baumgartner, stephan.baumgartner@kikom.unibe.ch

How to cite this article: Wälchli C, Baumgartner S. Flow cytometric analysis of the inhibition of human basophil activation by histamine high dilutions - a replication study. Int J High Dilution Res [online]. 2012 [cited YYYY Month dd]; 11(40):172-173. Proceedings of the XXVI GIRI Symposium; 2012 Sep 20-22; Florence (Italy). GIRI; 2012; Available from: http://www.feg.unesp.br/ ojs/index.php/ijhdr/article/view/588/588 